\title{
Numerical study on transient local entropy generation in pulsating turbulent flow through an externally heated pipe
}

\author{
HÜSEYIN YAPICI*,1 GAMZE BAŞTÜRK $^{1}$, NESRIN KAYATAŞ ${ }^{1}$ \\ and ŞENAY YALÇIN ${ }^{2}$ \\ ${ }^{1}$ Erciyes Üniversitesi Mühendislik Fakültesi Makine Mühendisliği Bölümü, \\ 38039 Kayseri, Turkey \\ ${ }^{2}$ Bahçeşehir Üniversitesi, Mühendislik Fakültesi, İstanbul, Turkey \\ e-mail: yapici@erciyes.edu.tr
}

MS received 5 November 2004; revised 28 April 2005

\begin{abstract}
This study presents an investigation of transient local entropy generation rate in pulsating turbulent flow through an externally heated pipe. The flow inlet to the pipe pulsates at a constant period and amplitude, only the velocity oscillates. The simulations are extended to include different pulsating flow cases (sinusoidal flow, step flow, and saw-down flow) and for varying periods. The flow and temperature fields are computed numerically with the help of the Fluent computational fluid dynamics (CFD) code, and a computer program developed by us by using the results of the calculations performed for the flow and temperature fields. In all investigated cases, the irreversibility due to the heat transfer dominates. With the increase of flow period, the highest levels of the total entropy generation rates increase logarithmically in the case of sinusoidal and saw-down flow cases whereas they are almost constant and the highest total local entropy is also generated in the step case flow. The Merit number oscillates periodically in the pulsating flow cases along the flow time. The results of this study indicate that flow pulsation has an adverse effect on the ratio of the useful energy transfer rate to the irreversibility rate.
\end{abstract}

Keywords. Pulsating pipe flow; local entropy generation; exergy; computational fluid dynamics.

\section{Introduction}

The study of pulsating flow in pipes has been a subject of interest among many researchers. A number of analytical and experimental investigations have been reported in recent years. Pulsating flows in circular pipes enhance heat transfer coefficients. In general, a pulsating flow field consists of a steady flow part and an oscillating part. The rate of heat transfer is altered because oscillation changes the thickness of the thermal boundary layer and hence the

*For correspondence

A list of symbols is given at the end of the paper 
thermal resistance. It was also demonstrated that the Nusselt number increases with increasing amplitude and frequency of oscillation (Cho \& Hyun 1990). Considerable research studies have been carried out to explore pulsating flow characteristics (Calmen \& Minton 1977; Faghri et al 1979; Kurzweg 1985; Cotta \& Ozisik 1986; Peattie \& Budwig 1989; Ahn \& Ibrahim 1992; Brown et al 1993; Valueva et al 1993; Moschandreou \& Zamir 1997; Al-Zaharnah et al 2001).

On the other hand, contemporary engineering thermodynamics uses a parameter called the rate of entropy generation (or production) to gauge the irreversibilities related to heat transfer, friction, and other non-idealities within systems. The second law of thermodynamics should be considered to evaluate the sources of irreversibility in flow and thermal systems. Conserving useful energy depends on designing efficient thermodynamic heat-transfer processes. Energy conversion processes are accompanied by an irreversible increase in entropy, which leads to a decrease in exergy (available energy). Thus, even though the energy is conserved, the quality of the energy decreases because the energy is converted into a different form of energy, from which less work can be obtained. Reduced entropy generation results in more efficient designs of energy systems. Therefore, in recent years, the entropy minimization has become a topic of great interest in the thermo-fluid area. Bejan (1996a) focused on the different reasons behind entropy generation in applied thermal engineering where the generation of entropy destroys the available work (exergy) of a system. Therefore, it makes good engineering sense to focus on the irreversibility of heat transfer and fluid flow processes, and try to understand the function of associated entropy generation mechanisms. Bejan (1996b) also carried out an extensive review on entropy generation minimization. The review traced the development and adoption of the method in several sectors of mainstream thermal engineering and science. Furthermore, many researchers carried out studies on the entropy generation in various flow cases. The second-law analysis of heat transfer in swirling flow through a cylindrical duct was investigated by Mukherjee et al (1987). They calculated the rate of entropy generation. They also defined a merit function and discussed the influence of swirling on this merit function. Mahmud \& Fraser $(2002,2003)$ investigated the second law analysis in fundamental convective heat transfer problems and the thermodynamic analysis of flow and heat transfer inside a channel with two parallel plates. Sahin (1998, 1999, 2000, 2002), Yilbas et al (1999), Shuja et al (1999, 2001b), Demirel \& Kahraman (1999), Abbassi et al (2003) and Hyder \& Yilbas (2002) performed many studies on second law analysis and the entropy generation due to the heat transfer and fluid friction in duct flows under various conditions. Shuja et al (2002, 2003) and Shuja \& Yilbas (2001) analysed the entropy generation in swirling jet impingement on an adiabatic wall and an impinging jet (Shuja et al 2001a) for various flow conditions. Furthermore, Haddad et al (2004) studied the entropy production due to laminar forced convection in the entrance region of a concentric cylindrical annulus, Abu-Hijleh et al (1999) calculated entropy generation due to natural convection for three radii and a wide range of Rayleigh numbers for an isothermal cylinder, and Yapici et al (2005) investigated the local entropy generation in a methane-air burner.

In the problem referred to as conjugate heat transfer, because the thermal boundary conditions along the solid-fluid interface are not known a priori, the energy equations should be solved under the conditions of continuity in the temperature and/or heat flux. The general theory of fluid motion is too difficult to enable the user to tackle arbitrary geometric configurations. It is possible to apply merely numerical techniques to arbitrary geometries. Therefore, a suitable numerical method and/or computational fluid dynamics (CFD) code is frequently used to solve the governing equations in this field. The CFD code is a program by which fluid flow can be predicted through arbitrary geometries, giving information such as 
flow speed, pressures, residence times, flow patterns etc. The main advantage of this approach is its potential for reducing the extent and number of experiments required to describe such types of flow.

Flow pulsation in externally heated pipes generates a pulsating temperature field, which in turn results in oscillating entropy generation within the pipe. The present study considers the transient local entropy generation rate due to the temperature and velocity gradients in pulsating turbulent flow through an externally heated pipe. In order to investigate the effect of the period of the pulsating flow on the entropy generation rate, pulsating flow is examined for various periods by using the Fluent CFD code (Fluent 2003).

\section{Mathematical model}

\subsection{Pipe geometry}

In this study, the numerical solution of the transient local entropy generation in pulsating turbulent flow through an externally heated pipe is analysed. Water is selected as fluid. The radius and length of the pipe are $R$ and $L$ respectively. The thickness of the pipe is neglected and the thermal boundary condition on the pipe wall is assumed to be uniform heat flux $q^{\prime \prime}$. The two-dimensional axisymmetric model of this considered pipe is shown in figure 1 . The flow inlet to the pipe is considered to be pulsating at a constant period and amplitude (only the velocity oscillates). The numerical calculation is performed for three different pulsating flow cases: (A) Sinusoidal flow, (B) step flow, and (C) saw-down flow (see figure 2). The effect of the frequency (or period, $\tau$ ) of the pulsating flow on the entropy generation rate is also investigated.

As is apparent from the above explanations, in this analysis, two phenomena are considered as follows: (i) the transient heat transfer inside the pipe and (ii) the transient local entropy generation in the fluid flow. The analysis is based on two-dimensional continuity, momentum, and energy equations.

\subsection{Mathematical model}

The assumptions made are as follows:

- the flow is transient two-dimensional axisymmetric, turbulent and incompressible;

- the thickness of the pipe is neglected;

- the no-slip condition is assumed at the pipe wall;

- the thermo-physical properties (except viscosity) of the fluid do not vary with temperature;

- the viscous heating is neglected.

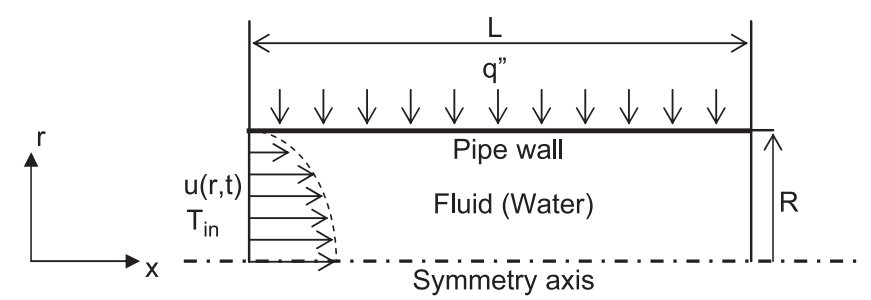

Figure 1. Coordinate system and two-dimensional axisymmetric model of the pipe (the dimensions are not to scale). 


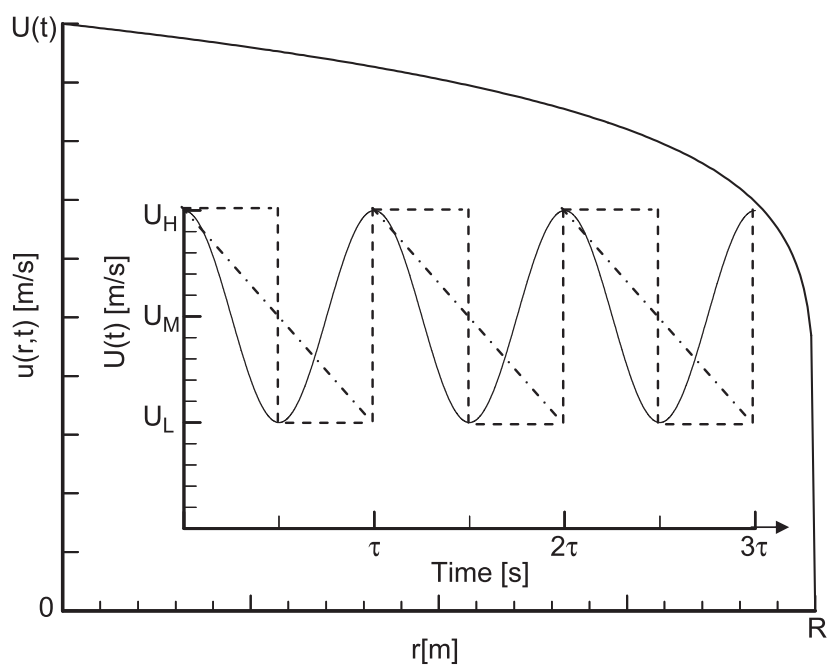

Figure 2. Variations of inlet velocity $[u(r, t)]:=$ in the case of sinusoidal flow (case A), - . - . - in the case of step flow (case B), ...... in the case of saw-down flow (case C).

2.2a The governing conservation equations: The governing equations for the transient turbulent incompressible flow and heat transfer in the flow region $(0 \leq x \leq L$ and $0 \leq r \leq R)$ can be written as follows:

Continuity:

$$
\frac{\partial u}{\partial x}+\frac{\partial v}{\partial r}+\frac{v}{r}=0 .
$$

Axial momentum:

$$
\begin{aligned}
\rho\left[\frac{\partial u}{\partial t}+\right. & \left.\frac{1}{r} \frac{\partial}{\partial x}(r u u)+\frac{1}{r} \frac{\partial}{\partial r}(r u v)\right] \\
= & -\frac{\partial P}{\partial x}+\frac{1}{r} \frac{\partial}{\partial x}\left\{r \mu\left[2 \frac{\partial u}{\partial x}-\frac{2}{3}\left(\frac{\partial u}{\partial x}+\frac{\partial v}{\partial r}+\frac{v}{r}\right)\right]\right\} \\
& +\frac{1}{r} \frac{\partial}{\partial r}\left[r \mu\left(\frac{\partial u}{\partial r}+\frac{\partial v}{\partial x}\right)\right] .
\end{aligned}
$$

Radial momentum:

$$
\begin{aligned}
\rho\left[\frac{\partial v}{\partial t}+\right. & \left.\frac{1}{r} \frac{\partial}{\partial x}(r u v)+\frac{1}{r} \frac{\partial}{\partial r}(r v v)\right] \\
= & -\frac{\partial P}{\partial r}+\frac{1}{r} \frac{\partial}{\partial x}\left[r \mu\left(\frac{\partial v}{\partial x}+\frac{\partial u}{\partial r}\right)\right] \\
& +\frac{1}{r} \frac{\partial}{\partial r}\left\{r \mu\left[2 \frac{\partial v}{\partial r}-\frac{2}{3}\left(\frac{\partial u}{\partial x}+\frac{\partial v}{\partial r}+\frac{v}{r}\right)\right]\right\} \\
& -2 \mu \frac{v}{r^{2}}+\frac{2}{3} \frac{\mu}{r}\left(\frac{\partial u}{\partial x}+\frac{\partial v}{\partial r}+\frac{v}{r}\right) .
\end{aligned}
$$


Energy:

$$
\rho C_{P}\left(\frac{\partial T}{\partial t}+u \frac{\partial T}{\partial x}+v \frac{\partial T}{\partial r}\right)=\lambda_{\text {eff }}\left[\frac{\partial^{2} T}{\partial x^{2}}+\frac{1}{r} \frac{\partial}{\partial r}\left(r \frac{\partial T}{\partial r}\right)\right]+\mu \Phi,
$$

where $\Phi$ is viscous dissipation term, which is

$$
\Phi=2\left[\left(\frac{\partial u}{\partial x}\right)^{2}+\left(\frac{\partial v}{\partial r}\right)^{2}+\left(\frac{v}{r}\right)^{2}\right]+\left(\frac{\partial v}{\partial x}+\frac{\partial u}{\partial r}\right)^{2},
$$

and $\lambda_{\text {eff }}$ is the effective thermal conductivity, and for the standard $k-\varepsilon$ model, is given by

$$
\lambda_{\text {eff }}=\lambda+\lambda_{t} \text { and } \lambda_{t}=C_{P} \mu_{t} / \operatorname{Pr}_{t} .
$$

Two additional equations for the standard $k-\varepsilon$ turbulence model:

The turbulence kinetic energy, $k$, and the dissipation rate, $\varepsilon$, are determined using the following transport equations, respectively:

$$
\begin{aligned}
& \rho \frac{D k}{D t}=\frac{\partial}{\partial x}\left(\left(\mu+\frac{\mu_{t}}{\sigma_{k}}\right) \frac{\partial k}{\partial x}\right)+\frac{1}{r} \frac{\partial}{\partial r}\left(r\left(\mu+\frac{\mu_{t}}{\sigma_{k}}\right) \frac{\partial k}{\partial r}\right)+G-\rho \varepsilon, \\
& \rho \frac{D \varepsilon}{D t}=\frac{\partial}{\partial x}\left(\left(\mu+\frac{\mu_{t}}{\sigma_{\varepsilon}}\right) \frac{\partial \varepsilon}{\partial x}\right)+\frac{1}{r} \frac{\partial}{\partial r}\left(r\left(\mu+\frac{\mu_{t}}{\sigma_{\varepsilon}}\right) \frac{\partial \varepsilon}{\partial r}\right)+\frac{\varepsilon}{k}\left(C_{1 \varepsilon} G-C_{2 \varepsilon} \rho \varepsilon\right),
\end{aligned}
$$

where

$$
G=\mu_{t} S^{2} \text { and } S^{2}=2\left[\left(\frac{\partial u}{\partial x}\right)^{2}+\left(\frac{\partial v}{\partial r}\right)^{2}+\left(\frac{v}{r}\right)^{2}\right]+\left(\frac{\partial v}{\partial x}+\frac{\partial u}{\partial r}\right)^{2},
$$

$\mu_{t}$ (turbulent viscosity) is computed by combining $k$ and $\varepsilon$ as follows:

$$
\mu_{t}=\rho C_{\mu}\left(k^{2} / \varepsilon\right),
$$

$C_{\mu}, C_{1 \varepsilon}$ and $C_{2 \varepsilon}$ are the model constants, $\sigma_{k}$ and $\sigma_{\varepsilon}$ are turbulent Prandtl numbers for $k$ and $\varepsilon$ respectively. They have the following default values (Launder \& Spalding 1972): $C \mu=$ $0.09, C_{\varepsilon 1}=1.44, C_{\varepsilon 2}=1.92, \sigma_{k}=1.0$ and $\sigma_{\varepsilon}=1.3$.

Furthermore, for the standard $k-\varepsilon$ model, the effective viscosity, $\mu_{\text {eff }}$, is defined as:

$$
\mu_{\mathrm{eff}}=\mu+\mu_{t}
$$

Boundary conditions:

At the pipe inlet $(x=0)$,

$$
u(0, r, t)=u(r, t), v(0, r, t)=0 \text { and } T(0, r, t)=T_{\text {in }}
$$

The inlet velocity, $u(r, t)$, is a pulsatile velocity and consists of two parts as follows:

$$
u(r, t)=U(t)(1-(r / R))^{1 / 7}
$$


where $U(t)$ is selected as:

in the case of no pulsating flow,

$$
U(t)=U_{M} ;
$$

in the case of sinusoidal flow (case A),

$$
U(t)=U_{M}+U_{A} \cos ((2 \pi / \tau) t) ;
$$

in the case of step flow (case B),

$$
U(t)= \begin{cases}U_{H}, & \text { if }(J-1) \tau<t \leq 0 \cdot 5(2 J-1) \tau, \\ U_{L}, & \text { otherwise, }\end{cases}
$$

in the case of saw-down flow (case C),

$$
U(t)=2 J U_{A}+U_{L}-2 U_{A} \frac{t}{\tau},
$$

where $U_{M}, U_{A}, U_{H}$ and $U_{L}$ are the mean (or vertical shift), amplitude, highest and lowest levels of the pulsatile velocity respectively. $U_{H}$ and $U_{L}$ can be calculated as follows:

$$
U_{H, L}=U_{M} \pm U_{A} .
$$

Since the profiles of velocity and temperature are both symmetric with respect to the axis of the pipe, the relevant boundary conditions at the pipe axis $(r=0)$ are

$$
\partial \phi(x, 0, t) / \partial r=0,
$$

where $\phi$ is any arbitrary variable.

At the pipe wall

$$
(r=R), v(x, R, t)=0,
$$

and the no-slip condition is assumed as follows:

$$
u(x, R, t)=0 .
$$

At the pipe inlet and exit planes $(x=0$ and $x=L)$,

$$
\partial T(0, r, t) / \partial x=0 \text { and } \partial T(L, r, t) / \partial x=0 .
$$

At the pipe wall $(r=R)$, a uniform heat flux is imposed,

$$
q^{\prime \prime}=q_{0}
$$

Initial condition:

$$
T(x, r, 0)=T_{0} .
$$


2.2b Entropy generation rate: In fluid flow, irreversibility arises due to the heat transfer and the viscous effects of the fluid. In order to obtain the volumetric entropy generation rate distribution, it is assumed that the pipe reaches thermal equilibrium at the end of each time step, $(\Delta t)$. In these systems, when both temperature and velocity fields are known, the volumetric entropy generation rate $\left(S_{\mathrm{gen}}^{\prime \prime \prime}\right)$ at each point in the system can be calculated for each time step as follows (Bejan 1996a):

$$
S_{\mathrm{gen}}^{\prime \prime \prime}=\left(S_{\mathrm{gen}}^{\prime \prime \prime}\right)_{\text {heat }}+\left(S_{\mathrm{gen}}^{\prime \prime \prime}\right)_{\text {fric }},
$$

where $\left(S_{\text {gen }}^{\prime \prime \prime}\right)_{\text {heat }}$ and $\left(S_{\text {gen }}^{\prime \prime \prime}\right)_{\text {fric }}$ represent the entropy generation rates due to heat transfer and fluid friction respectively, and are defined as:

$$
\begin{aligned}
\left(S_{\text {gen }}^{\prime \prime \prime}\right)_{\text {heat }} & =\left(\lambda_{\text {eff }} / T^{2}\right)\left[(\partial T / \partial x)^{2}+(\partial T / \partial r)^{2}\right], \\
\left(S_{\text {gen }}^{\prime \prime}\right)_{\text {fric }} & =\left(\mu_{\text {eff }} / T\right) \Phi .
\end{aligned}
$$

The total entropy generation rate over the volume $\left(\dot{S}_{\text {gen }}\right)$ can be calculated as follows:

$$
\dot{S}_{\text {gen }}=\oint_{V} S_{\text {gen }}^{\prime \prime \prime} \partial \theta \partial r \partial x
$$

where $V$ is the volume.

Furthermore, the integration of the total entropy generation rate on the time interval $t_{1}$ to $t_{2}$ gives the total entropy generation in this time interval, $S_{\text {gen }}$, i.e.:

$$
S_{\text {gen }}=\int_{t_{1}}^{t_{2}} \dot{S}_{\text {gen }}(t) \mathrm{d} t
$$

The Bejan number, Be, which compares the magnitude of entropy generation due to heat transfer to the magnitude of the total entropy generation, is defined by:

$$
\mathrm{Be}=\left(\dot{S}_{\text {gen }}\right)_{\text {heat }} / \dot{S}_{\text {gen }} \text {. }
$$

When $\mathrm{Be} \gg 0.5$, the irreversibility due to heat transfer dominates, while for $\mathrm{Be} \ll 0.5$ the irreversibility due to viscous effects dominates. For $\mathrm{Be} \cong 0 \cdot 5$, entropy generation due to heat transfer is almost of the same magnitude as that due to fluid friction.

The rate of total irreversibility $(\dot{I})$ is defined as:

$$
\dot{I}=T_{\mathrm{amb}} \cdot \dot{S}_{\mathrm{gen}} .
$$

The rate of exergy transfer $\left(\dot{Q}_{a}\right)$ accompanying energy transfer at the rate of $\dot{Q}$ is given as (Mukherjee et al 1987):

$$
\dot{Q}_{a}=\dot{Q}\left[1-\left\{T_{a m b} /\left(T_{w}\right)_{a w a}\right\}\right] .
$$

The Merit number (M) is defined as the ratio of exergy transferred to the sum of exergy transferred and exergy destroyed (Mukherjee et al 1987), i.e.:

$$
M=\dot{Q}_{a} /\left(\dot{Q}_{a}+\dot{I}\right) .
$$


"awa" represents area-weighted average of relevant quantity. The area-weighted average of a quantity is computed by dividing the summation of the product of the selected field variable $\left(\psi_{j}\right)$ and facet area $\left(A_{j}\right)$ by the total area of relevant surface, $(A)$ :

$$
(\psi)_{a w a}=\frac{1}{A} \sum_{j=1}^{n} \psi_{j}\left|A_{j}\right| .
$$

To obtain the total entropy generation rate, it is necessary first to solve the governing conservation equations given in section 2.2a. The volumetric local entropy generation rate can be calculated using the local velocities and temperatures obtained from the calculations of the governing conservation equations, and the total entropy generation rate over the volume can be obtained using numerical integration.

\section{Computational procedure}

\subsection{Calculational tools}

Even the difficult general differential equations now yield to the approximating technique known as numerical analysis, whereby the derivates are simulated by algebraic relations between a finite numbers of grid points in the flow field which are then solved on a digital computer. A suitable CFD computer code can be used to solve numerically the governing equations (1)-(4) along with the boundary condition equation (5a-n) and the initial condition equation (6). The CFD program is a process by which fluid flow can be predicted through arbitrary geometries giving such information as flow speed, pressures, residence times, flow patterns etc.

The Fluent $6 \cdot 1$ (Fluent 2003) program was chosen as the CFD computer code for this work because of the ease with which the analysis model can be created, and because the software allows users to modify the code for special analysis conditions through the use of user subroutines. The Fluent computer code uses a finite-volume procedure to solve the governing equations of fluid flow in primitive variables such as $u$-velocity, $v$-velocity, and pressure. A variety of turbulence models is offered by the Fluent computer code. The standard $k-\varepsilon$ model (Fluent 2003) was used as a turbulence model in this study. The standard $k-\varepsilon$ model is a semi-empirical model based on model transport equations for the turbulent kinetic energy $(k)$ and its dissipation rate $(\varepsilon)$. The model transport equation for $k$ is derived from the exact equation while the model transport equation for $\varepsilon$ is obtained using physical reasoning and bears little resemblance to its mathematically exact counterpart. In the derivation of the $k-\varepsilon$ model, it was assumed that the flow is fully turbulent, and the effects of molecular viscosity are negligible. The standard $k-\varepsilon$ model is, therefore, valid only for fully turbulent flows. A detailed description of turbulence models and its application to turbulence can be found in ref. (Fluent 2003; Launder \& Spalding 1972). In the case of the standard $k-\varepsilon$ models, two additional transport equations, $(4 \mathrm{a}, \mathrm{b})$ with sub-equations $(4 \mathrm{c}-\mathrm{f})$, (for the turbulent kinetic energy and the turbulence dissipation rate) are solved, and turbulent viscosity, $\mu_{t}$, is computed as a function of $k$ and $\varepsilon$. The solution method for this study is axisymmetric.

In order to define the pulsating inlet velocities in all cases, an UDF (User-Defined Function) file was introduced to the prepared Fluent case file. The UDF files provide the capability to customize boundary conditions, source terms, property definitions (except specific heat), surface and volume reaction rates, user-defined scalar transport equations, discrete phase model (e.g. body force, drag, source terms), algebraic slip mixture model (slip velocity and 
particle size), solution initialization, wall heat fluxes and post processing using user-defined scalars, and thus can significantly enhance the capability of Fluent. Furthermore, a computer program has been developed to numerically calculate the volumetric entropy generation rate distributions in equations $(7 \mathrm{a}-\mathrm{c})$ and other thermodynamic parameters in $(7 \mathrm{~d}-\mathrm{i})$, by using the results of the calculations performed with the Fluent code. This program, written in FORTRAN 77 language, calculates numerically the axial and radial derivations of the temperature $(T)$ and the components $\left(u_{x}\right.$ and $\left.u_{r}\right)$ of velocity, which are the function of the axial and radial distances. It uses the finite-differences approach, and thus it calculates the volumetric entropy generation rate distributions as two dimensional, and the other thermodynamic parameters.

\subsection{Simulation values}

$R=0.02 \mathrm{~m}$ and $L=1 \mathrm{~m}$.

$\dot{Q}=10000 \mathrm{~W}$ corresponding to $q_{0}=79577.5 \mathrm{~W} / \mathrm{m}^{2}$.

$T_{\text {amb }}=T_{\text {in }}=T_{0}=273 \mathrm{~K}, U_{M}=0.2 \mathrm{~m} / \mathrm{s}$, and $U_{A}=0.1 \mathrm{~m} / \mathrm{s}$.

For the numerical integration of the transient equations, the time-step $\Delta t=0 \cdot 1$.

$t_{\max }=360 \mathrm{~s}$ and $\tau=30,45,60,90,120$, and $180 \mathrm{~s}$.

For water, $\rho=1000 \mathrm{~kg} / \mathrm{m}^{3}, C_{P}=4182 \mathrm{~J} / \mathrm{kg}-\mathrm{K}, \lambda=0.6 \mathrm{~W} / \mathrm{m}-\mathrm{K}$, and the temperaturedependent viscosity is given by (Yaws et al 1994):

$$
\mu(T)=1.788 \cdot 10^{-3} \exp \left(-1.704-5.306(273 / T)+7.003(273 / T)^{2}\right)
$$

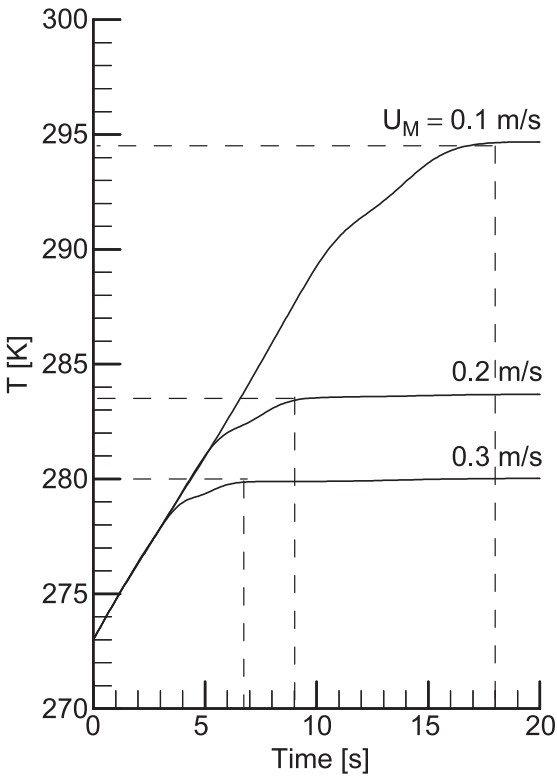

Figure 3. Variations of the average outlet temperature for the various $U_{M} \mathrm{~s}$ in the case of no-pulsating flow depending on flow time. 
At the inlet, the mass flow rate $(\dot{m})$ and the total mass $(m)$ in the time interval $t_{1}$ to $t_{2}$ can be calculated as follows:

$$
\dot{m}(t, r)=\rho \pi\left\lfloor(r+\Delta r)^{2}-r^{2}\right\rfloor \cdot u(t, r) \text { and } m=\int_{t_{1}}^{t_{2}}\left[\sum_{r} \dot{m}(t, r)\right] \cdot \mathrm{d} t,
$$

where $\Delta r=0.001 \mathrm{~m}$.

In all the flow and period cases considered, the total mass in the time interval 0 to $t_{\max }$ has the same value $(75.605 \mathrm{~kg})$.

(a)

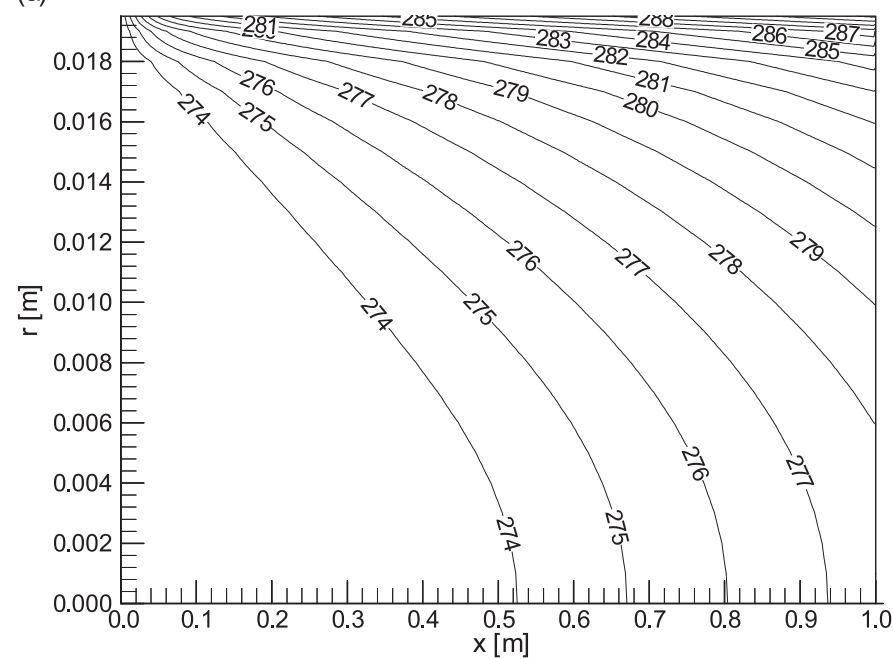

(b)

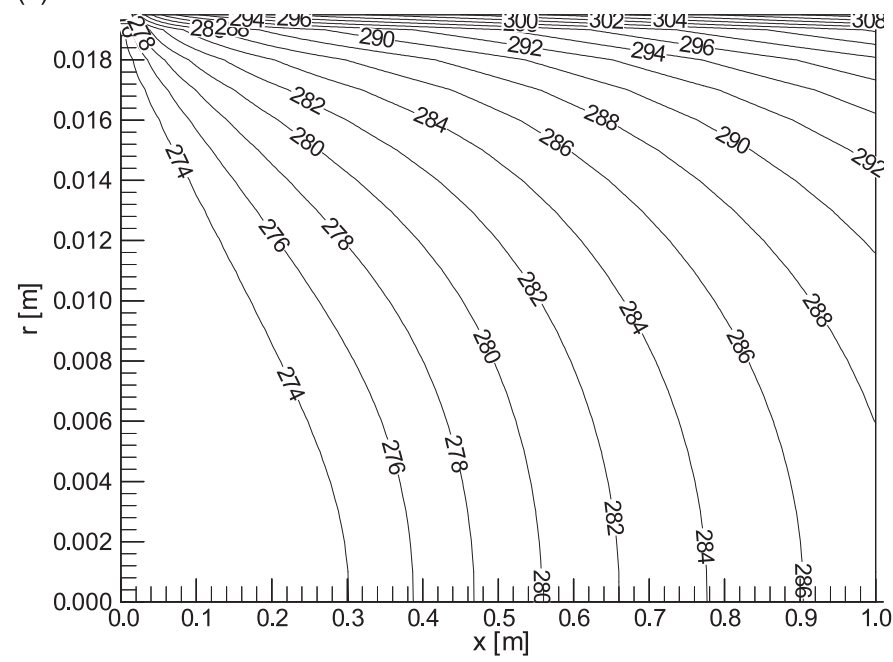

Figure 4. Temperature contours within the pipe at the times that the inlet velocity reaches (a) its highest $(0.3 \mathrm{~m} / \mathrm{s})$ and $(\mathbf{b})$ lowest $(0.1 \mathrm{~m} / \mathrm{s})$ levels (flow case $\mathrm{A})$. 
Grid size: Grid-independent tests were carried out to ensure grid independence of the calculated results; consequently, the grid size and the grid orientation giving grid independent results were selected, and thus a total cell number of 10000 cells $(500 \times 20)$ was adopted.

\section{Numerical results}

\subsection{Temperature distributions}

In order to determine the times converging to the steady-state (the converging time), numerical calculations were also performed for three different $U_{M} \mathrm{~s}(0 \cdot 1,0 \cdot 2$ and $0 \cdot 3 \mathrm{~m} / \mathrm{s})$ in the case of
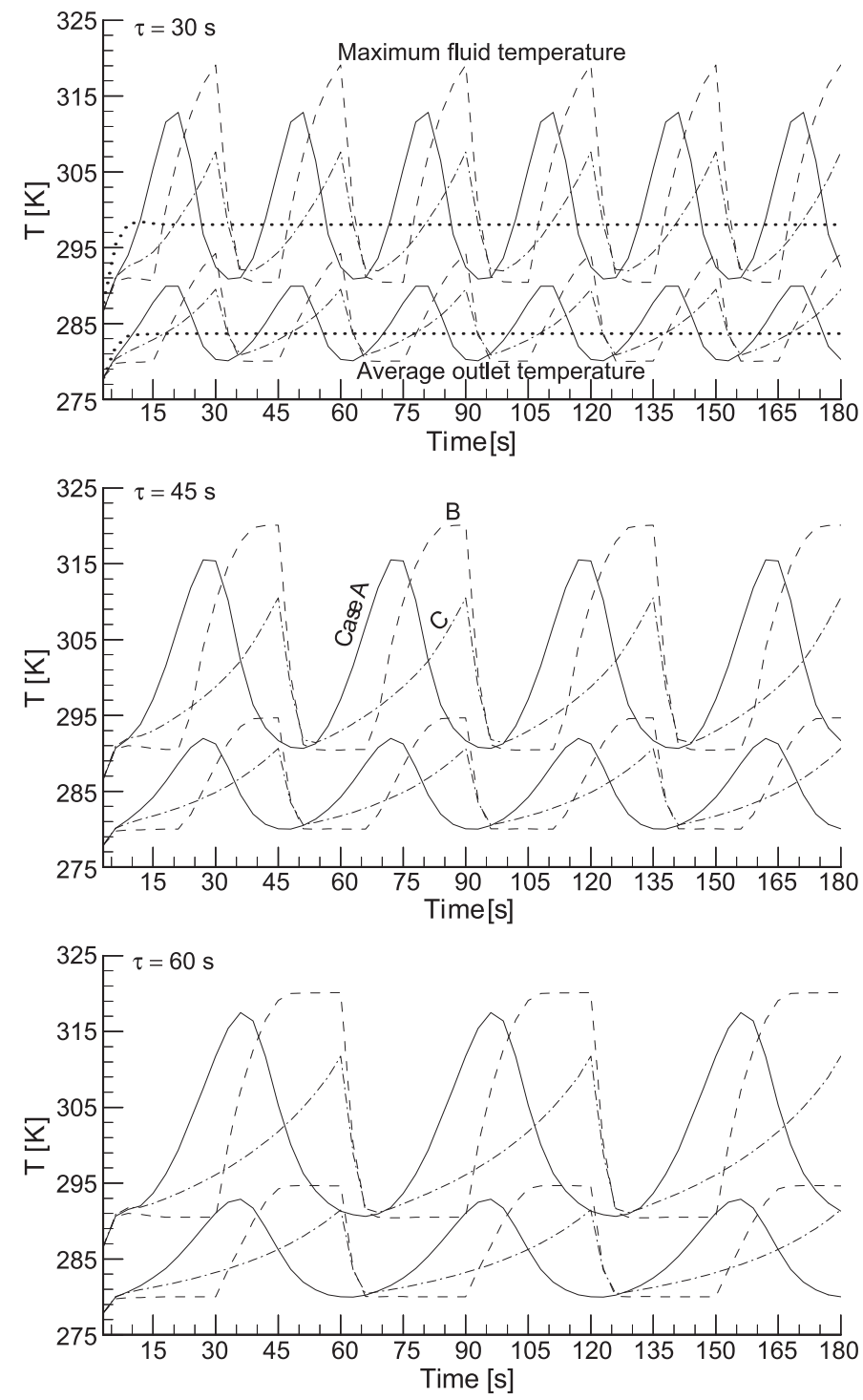

Figure 5(a). Variations of the maximum fluid temperature and the average outlet temperature depending on the flow time (the dotted lines in the first sub-graph are for the case of no-pulsating flow). 
no pulsating flow. Figure 3 shows the increase of average outlet temperatures for these $U_{M} \mathrm{~s}$ depending on the flow time. The converging times for the $U_{M} \mathrm{~s}$ are extracted approximately from these curves. As apparent from this figure, the converging time decreases from about 18 to $7 \mathrm{~s}$ with the increase of $U_{M}$, from 0.1 to $0.3 \mathrm{~m} / \mathrm{s}$. The average outlet temperatures corresponding to the converging times, 18 and $7 \mathrm{~s}$, are 294.5 and $280 \mathrm{~K}$, respectively (for $U_{M}=0.2 \mathrm{~m} / \mathrm{s}$, these values are $9 \mathrm{~s}$ and $283.5 \mathrm{~K}$ ).

The temperatures within the pipe at the times that the inlet velocity reaches its highest $(0.3 \mathrm{~m} / \mathrm{s})$ and lowest $(0.1 \mathrm{~m} / \mathrm{s})$ levels are contoured in figure 4 for the case of sinusoidal flow.
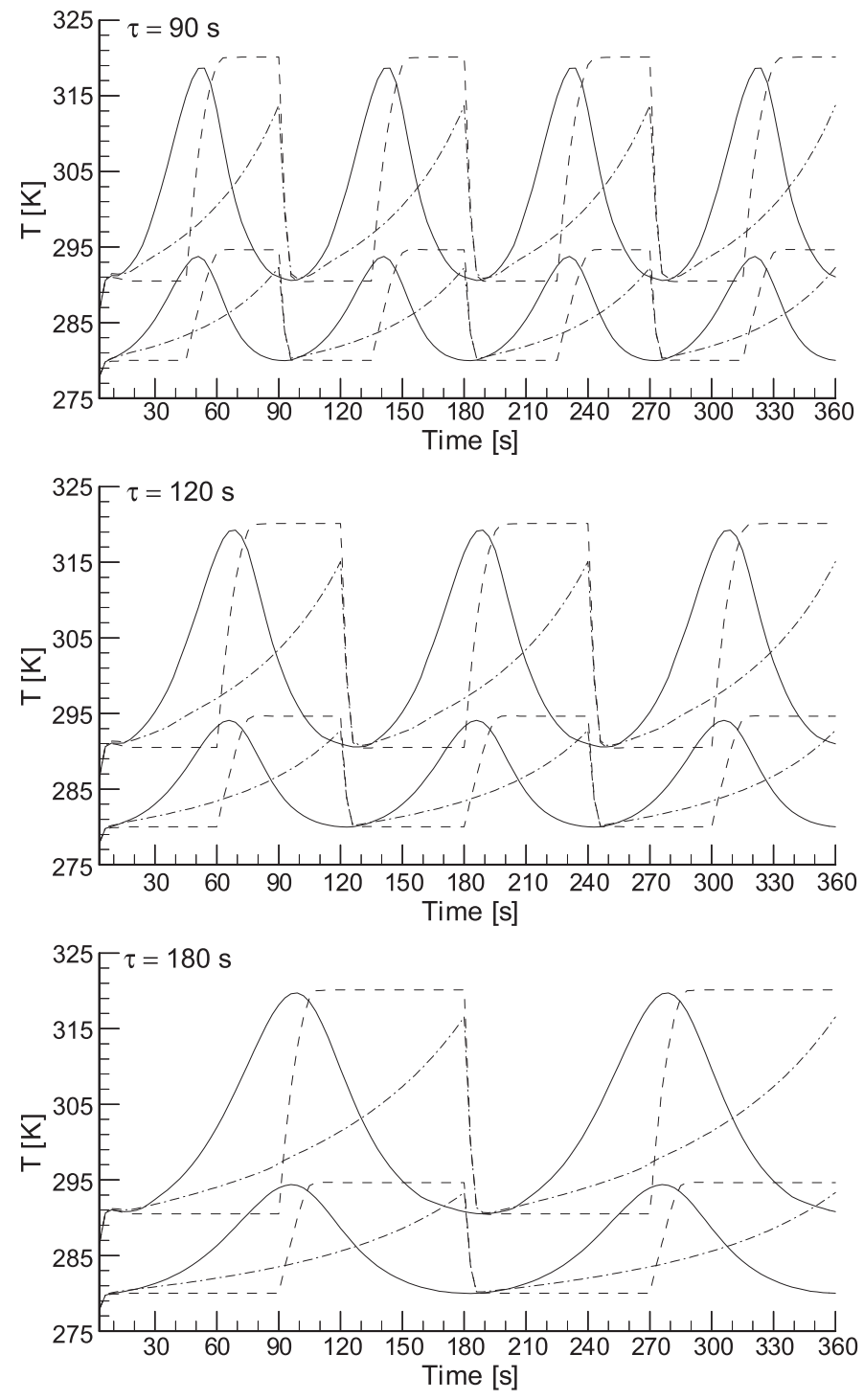

Figure 5(b). Variations of the maximum fluid temperature and the average outlet temperature depending on the flow time. 

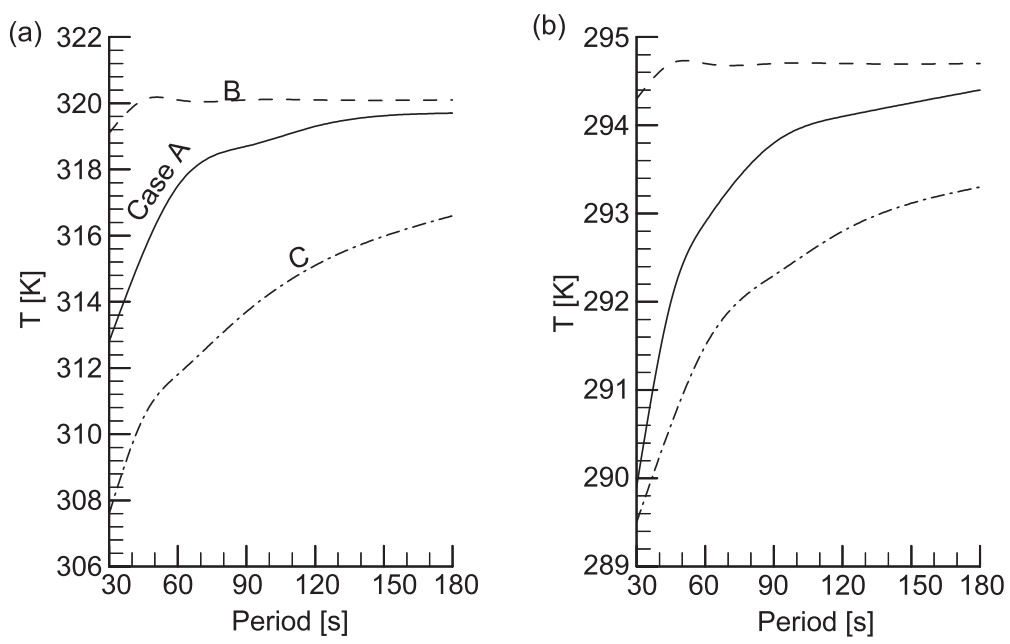

Figure 6. The highest levels of (a) the maximum fluid temperature and (b) the average outlet temperature versus the flow period.

Due to the fact that the pipe wall is exposed to the uniform heat flux, its temperature rises continuously and heat penetration takes place in the radial direction. However, the centreline temperature between $x=0$ and $0.5 \mathrm{~m}$ does not change significantly because sufficient heat does not penetrate into this region. The constant temperature contours extend further inside the fluid, and the high temperature contours are developed in the region close to the pipe wall as the pipe length extends. This is because of the convective heating of the fluid in the vicinity of the pipe wall. Furthermore, the effect of the inlet velocity variation on the temperature within the fluid is also apparent in figure 4. As is known, the increase of fluid velocity in the flow through the externally heated pipe decreases the temperature of the fluid.

Figures $5 \mathrm{a}, \mathrm{b}$ exhibit the variations of the maximum fluid temperature $\left(T_{\max }\right)$ and the average outlet temperature $\left(T_{\text {out }}\right)$ in all considered flow cases with the flow time. In the case of no pulsating flow $\left(U_{M}=0.2 \mathrm{~m} / \mathrm{s}\right)$, the maximum fluid temperature reaches $297.5 \mathrm{~K}$ in a short time (the converging time belonging to this $U_{M}$ ) and then it remains quasi-constant at this level along the heating process. In the pulsating flow cases, the transient maximum and average temperature profiles have similar behaviour with periodic variation of the inlet velocity due to the fact that flow pulsation in externally heated pipes generates a pulsating temperature field. First, they increase for a short time (6-7 s), then oscillate periodically with a period equal to that of the inlet velocity. However, periodic variations are the reverse of the inlet velocity, i.e. as the inlet velocity decreases or increases, the temperature profile increases or decreases respectively. The lowest levels of $T_{\max }$ and $T_{\text {out }}$ in all pulsating flow cases are almost equal to each other $\left(T_{\max }=290 \mathrm{~K}\right.$ and $\left.T_{\text {out }}=280 \mathrm{~K}\right)$. Their highest levels are plotted versus the flow period in figure 6 . One can see in this figure that as the flow period increases (from 30 to $180 \mathrm{~s}$ ), these highest levels increase logarithmically in the flow cases A ( $T_{\max }=313$ to $319 \mathrm{~K}$ and $T_{\text {out }}=290$ to $294 \mathrm{~K}$ ) and C (308 to $315 \mathrm{~K}$ and 289 to $292 \mathrm{~K}$ ) whereas they almost do not change in the flow case B ( $321 \mathrm{~K}$ and $295 \mathrm{~K})$. Consequently, the highest temperatures occur in the flow case B, followed by A, and $\mathrm{C}$. 

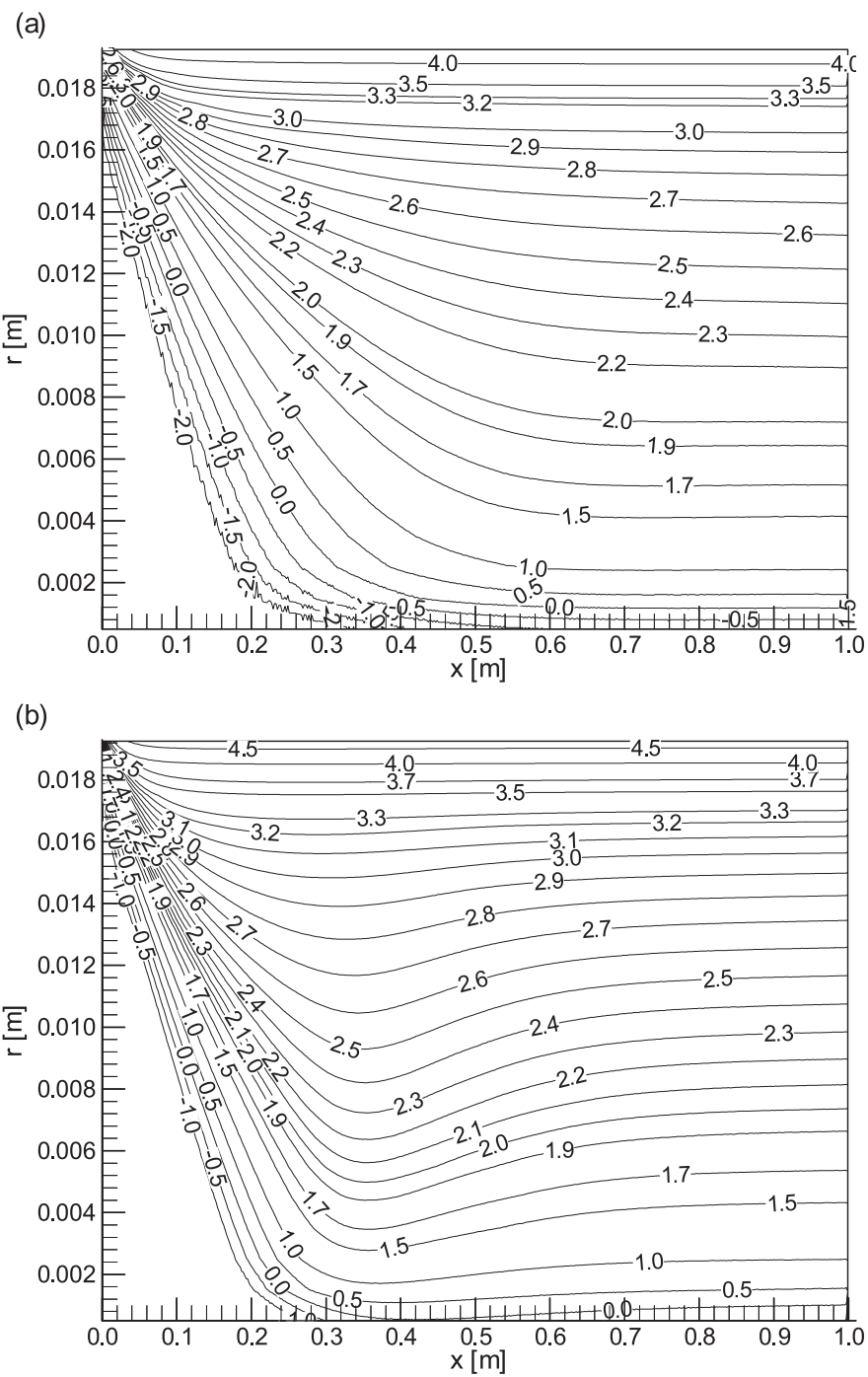

Figure 7. Logarithmic volumetric local entropy generation rate contours within the pipe at the times that the inlet velocity reaches (a) its highest $(0.3 \mathrm{~m} / \mathrm{s})$ and (b) lowest $(0.1 \mathrm{~m} / \mathrm{s})$ levels (flow case A).

\subsection{The local entropy generation}

The heat transferred into the flowing fluid increases the temperature of this fluid, and so it causes the large temperature gradients, that increase the local entropy generation due to the heat transfer (see (7b)), within the pipe. In other words, the local entropy generation in a flow is related to the temperature gradient occurring in that flow. The calculations bring out that in all investigated cases, the entropy generation rates due to the fluid friction are quite low with respect to those due to the heat transfer, i.e. the Bejan number, Be, is very close to 1 (about 0.996). As a result, it means that the irreversibility due to the heat transfer dominates.

Figure 7 shows the volumetric local entropy generation rate contours within the pipe at the times that the inlet velocity reaches its highest $(0.3 \mathrm{~m} / \mathrm{s})$ and lowest $(0.1 \mathrm{~m} / \mathrm{s})$ levels for the 

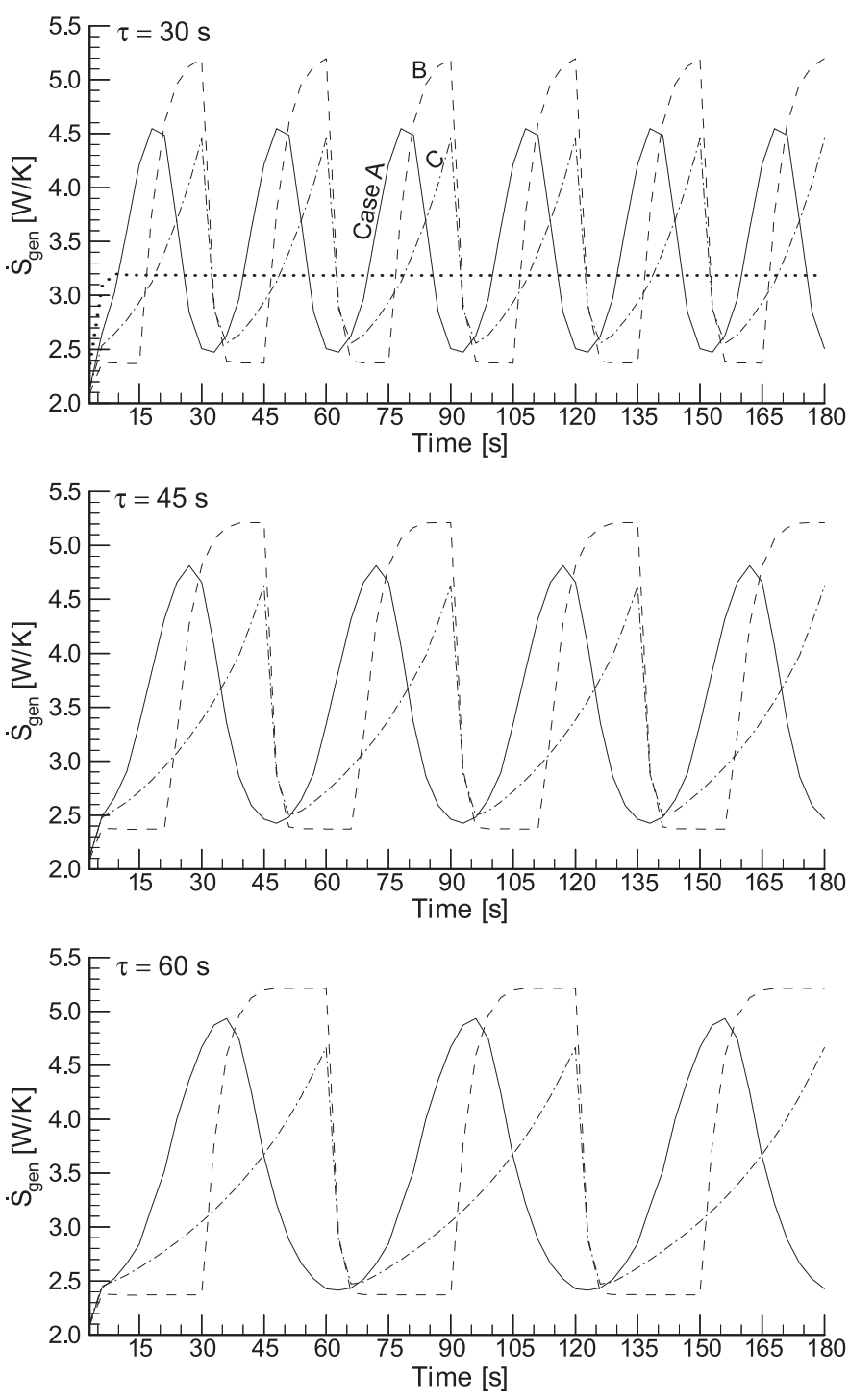

Figure 8(a). Variations of entropy generation rate over the volume depending on the flow time (the dotted line in the first sub-graph is for the case of no pulsating flow).

case of sinusoidal flow as logarithmic values. The volumetric local entropy generation rate contours do not resemble the temperature contours. This is because the entropy generation is proportional to the temperature gradient rather than temperature. As the thermal penetration takes place along the pipe length, the local entropy generation region widens but the peak value of volumetric local entropy generation rate decreases. In regions near the wall, the volumetric local entropy generation rate increases sharply, and then remains quasi-constant along the pipe length. However, it is very close to zero along the centreline due to the fact that the radial temperature gradient is zero and the velocity gradients are either very small 

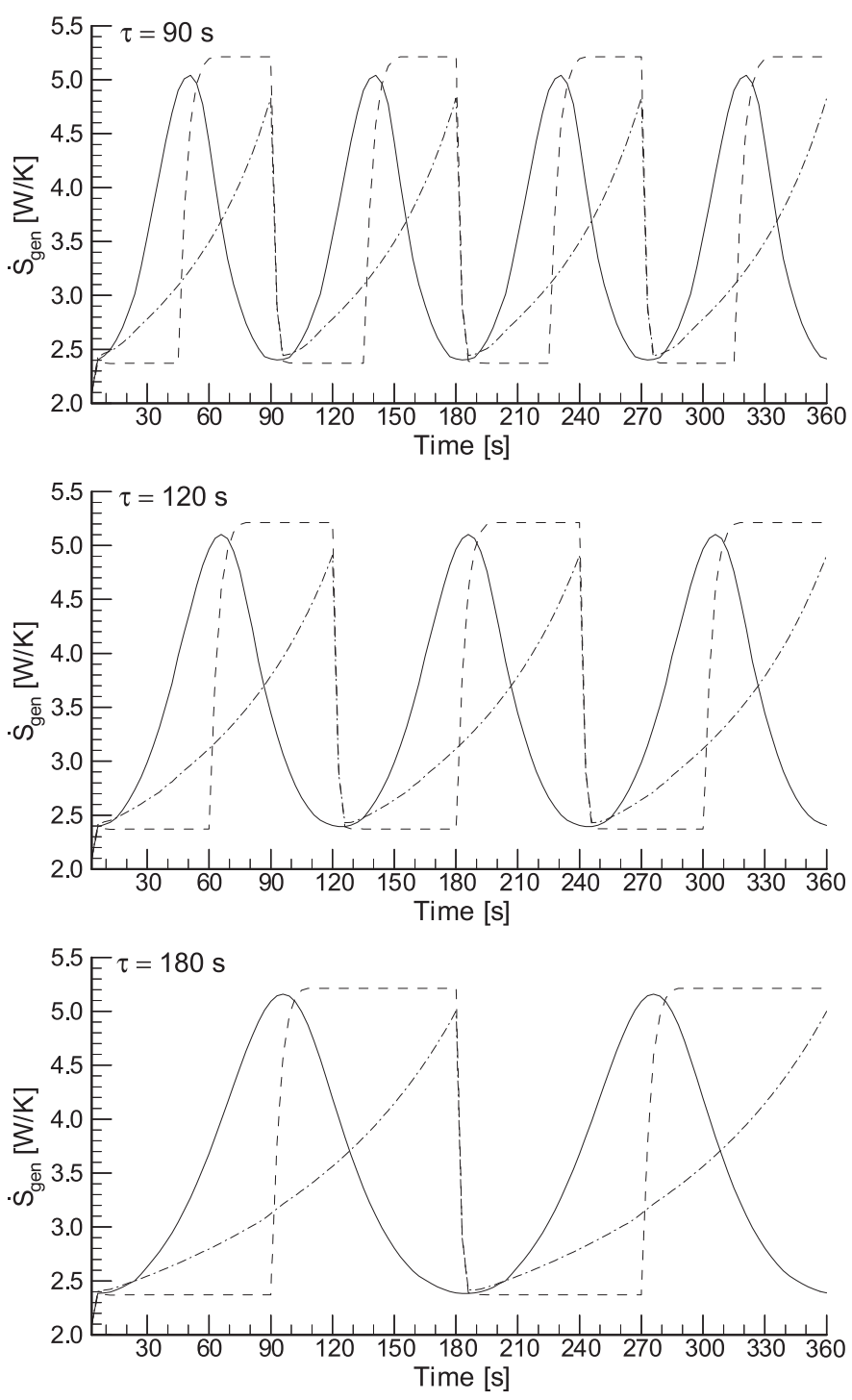

Figure 8(b). Variations of entropy generation rate over the volume depending on the flow time.

or zero. Moreover, the increase of fluid velocity also decreases the volumetric local entropy generation rate.

The variations of the total entropy generation rate $\left(\dot{S}_{\text {gen }}\right)$ and the exergy transfer rate $\left(\dot{Q}_{a}\right)$ with flow time in all the flow cases considered are plotted in figures 8a,b and 9a,b respectively. In the case of no pulsating flow, after converging to the steady-state, $\dot{S}_{\text {gen }}$ and $\dot{Q}_{a}$ remain at constant values of $3.3 \mathrm{~W} / \mathrm{K}$ and $2280 \mathrm{~W}$ respectively, along the heating process. However, their transient variations in all pulsating flow cases exhibit similar behaviour with the transient temperatures as explained in $\S 4.1$, i.e. they also oscillate periodically with period equal to the period of inlet velocity. The lowest levels of $\dot{S}_{\text {gen }}$ in all 

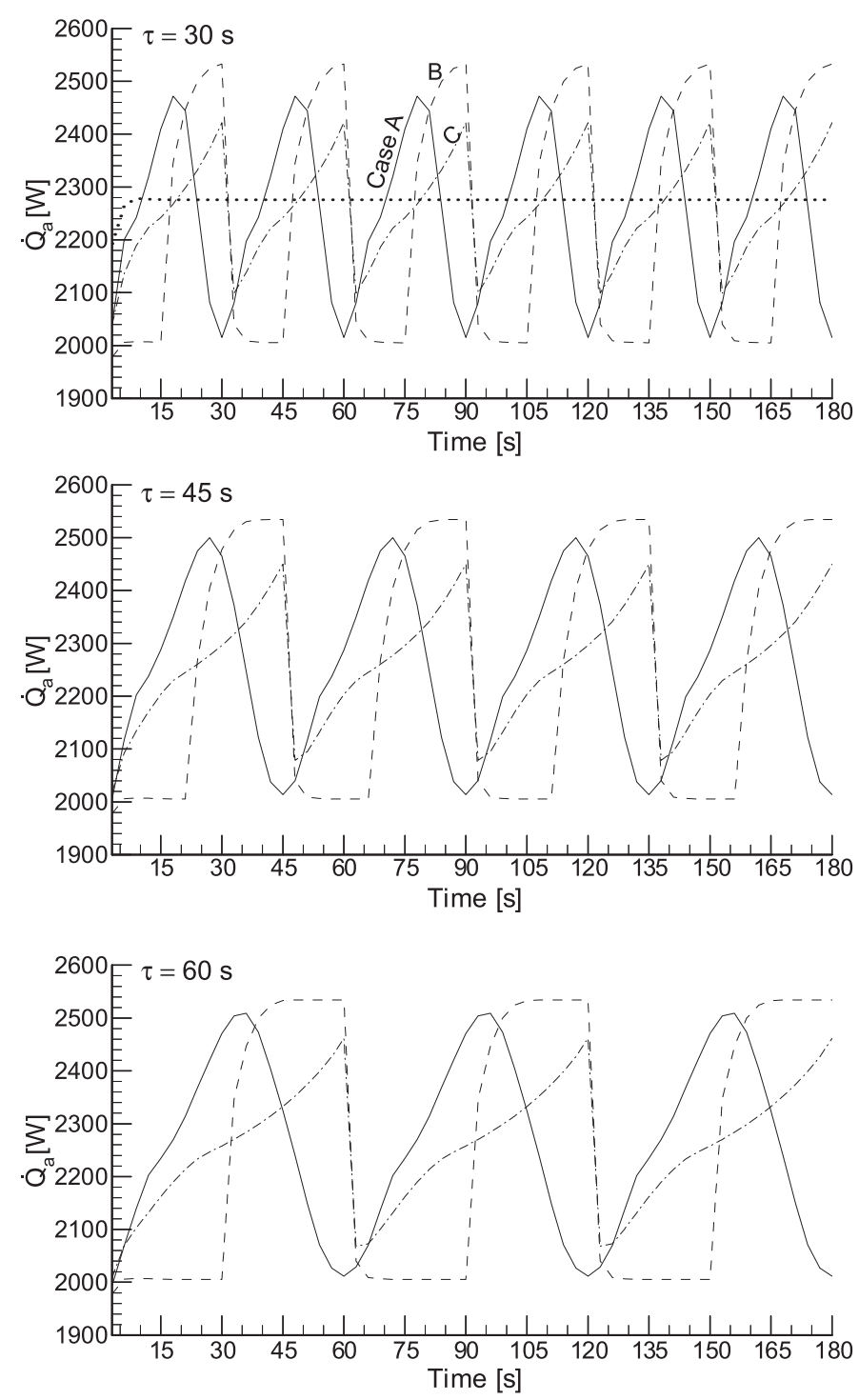

Figure 9(a). Variations of exergy transfer rate depending on the flow time (the dotted line in the first sub-graph is for the case of no pulsating flow).

pulsating flow cases are almost equal to each other (about $2.4 \mathrm{~W} / \mathrm{K}$ ). This level is about $2000 \mathrm{~W}$ for $\dot{Q}_{a}$. Their highest levels are plotted versus the flow period in figure 10. It is apparent from this figure that with the increase of flow period (from 30 to $180 \mathrm{~s}$ ), these highest levels increase logarithmically in the flow cases A ( $\dot{S}_{\text {gen }}=4.55$ to $5.16 \mathrm{~W} / \mathrm{K}$ and $\dot{Q}_{a}=2470$ to $\left.2530 \mathrm{~W}\right)$ and $\mathrm{C}(4.46$ to $4.99 \mathrm{~W} / \mathrm{K}$ and 2421 to $2505 \mathrm{~W})$ whereas they almost do not change in the flow case B (about $5.2 \mathrm{~W} / \mathrm{K}$ and about $2534 \mathrm{~W}$ ). These results bring out that the highest total local entropy is generated in the flow case B, followed by A and $\mathrm{C}$. 



Figure 9(b). Variations of exergy transfer rate depending on the flow time.

The total entropy generations, $S_{\mathrm{gen}} \mathrm{s}$ in J/K, obtained from the integration of the total entropy generation rate on the time intervals 0 to $t_{\max }$ and one period (see (7e)) are given in table 1 for all the period cases considered. In all the flow and period cases, the total mass in the time interval 0 to $t_{\max }$ is $75.605 \mathrm{~kg}$. In all the pulsating flow cases, the increase of period logarithmically increases the total entropy generation. Consequently, the pulsating flow increases the entropy generation more than the no-pulsating flow. The total entropy generation in the time interval $N$ periods ( $N$ is any integer), can be easily estimated by using the values of $S_{\text {gen }}$ per period given in this table.

Figures $11 \mathrm{a}, \mathrm{b}$ depict the variations of the Merit number (M) with flow time in all the flow cases considered. In the case of no-pulsating flow, the value of M is 0.725 . Due to the fact 

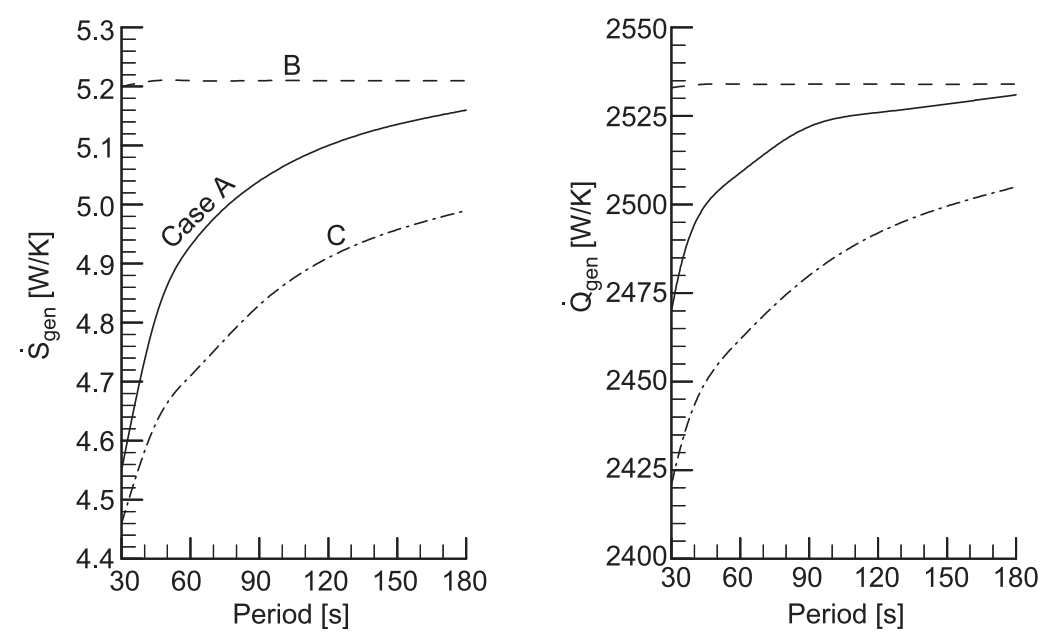

Figure 10. The highest levels of the total entropy generation rate and the exergy transfer rate versus the flow period.

that the Merit number is the ratio of exergy transferred to the sum of exergy transferred and exergy destroyed (see (7i) and the variation of $\dot{S}_{\text {gen }}$ has similar behaviour to that of $\dot{Q}_{a}$, it also oscillates periodically with their periods. The lowest levels of M are around 0.660 (8\% lower than $M=0.725)$ whereas its highest levels in all pulsating flow cases are almost equal to each other, about 0.755 ( $4 \%$ higher than $M=0.725$ ). These values indicate that the pulsing of the flow negatively influences the useful energy transfer rate to the irreversibility rate.

\section{Conclusions}

The numerical solution of the transient local entropy generation in pulsating turbulent flow through a pipe, exposed to a uniform heat flux from its wall, was analysed for three different flow cases. Water is selected as fluid. The effect of the period of the pulsating flow on the

Table 1. Total entropy generation, $S_{\text {gen }}$ in $\mathrm{J} / \mathrm{K}$, in the period cases considered.

\begin{tabular}{|c|c|c|c|c|c|c|}
\hline \multirow{3}{*}{$\begin{array}{l}\text { Period } \\
\text { [s] } \\
-\end{array}$} & \multicolumn{6}{|c|}{ Flow case } \\
\hline & \multicolumn{2}{|c|}{ Sinusoidal } & \multicolumn{2}{|c|}{ Step } & \multicolumn{2}{|c|}{ Saw-down } \\
\hline & $1136^{a, b}$ & - & 1136 & - & 1136 & - \\
\hline 30 & $1215^{b}$ & $102^{c}$ & 1285 & 108 & 1157 & 97 \\
\hline 45 & 1226 & 154 & 1315 & 166 & 1162 & 147 \\
\hline 60 & 1231 & 206 & 1321 & 222 & 1167 & 196 \\
\hline 90 & 1236 & 311 & 1329 & 336 & 1176 & 297 \\
\hline 120 & 1237 & 415 & 1335 & 450 & 1180 & 398 \\
\hline 180 & 1240 & 624 & 1341 & 677 & 1185 & 599 \\
\hline
\end{tabular}

${ }^{a}$ In the case of no-pulse; ${ }^{b}$ in the time intervals 0 to $360 \mathrm{~s} ;{ }^{c}$ one period 



Figure 11(a). Variations of Merit number depending on the flow time (the dotted line in the first sub-graph is for the case of no-pulsating flow).

entropy generation rate was also investigated. The specific conclusions derived from this study can be listed briefly as follows:

- The transient temperatures within the pipe in the pulsating flow cases oscillate periodically with a period equal to the period of the inlet velocity.

- The highest temperature occurs in the step flow case $\left(T_{\max }=321 \mathrm{~K}\right)$.

- In all investigated cases, the irreversibility due to the heat transfer dominates (Bejan number, Be, is very close to 1 ).

- The transient total entropy generation rates in all pulsating flow cases also oscillate periodically with a period equal to that of the inlet velocity. 

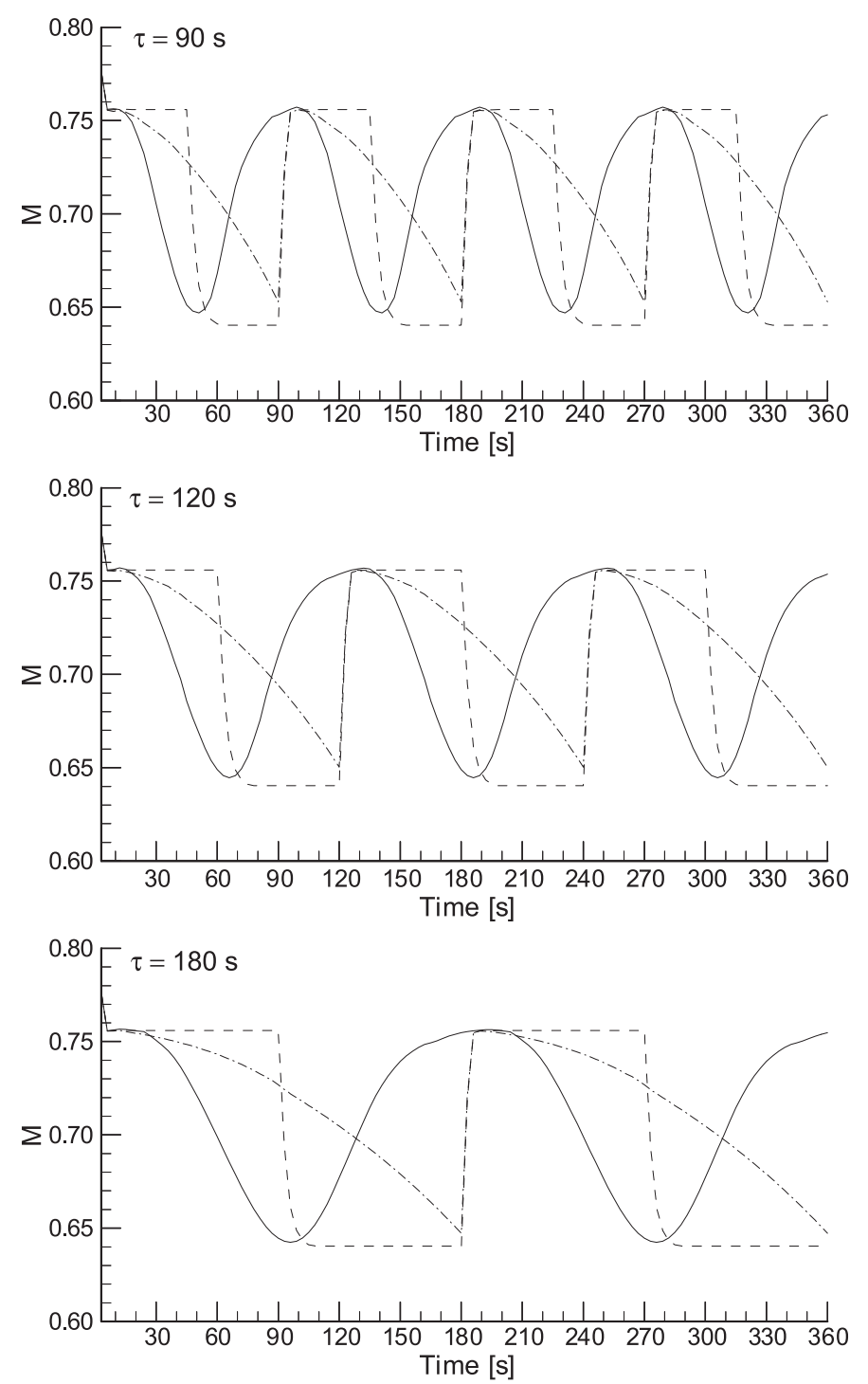

Figure 11(b). Variations of Merit number depending on the flow time.

- With the increase of flow period, the highest levels of the total entropy generation rates increase logarithmically in the case of sinusoidal and saw-down flow cases, whereas they do not almost change in the step-flow case.

- The highest total local entropy is generated in the step-flow case $(5 \cdot 2 \mathrm{~W} / \mathrm{K})$.

- While in the case of no-pulsating flow, the value of Merit number is 0.725 , it oscillates periodically in the range of 0.660 to 0.755 in the pulsating flow cases along with flow time.

- The results of this study indicate that flow pulsation has an adverse effect on the ratio of the useful energy transfer rate to the irreversibility rate. 


\section{List of symbols}

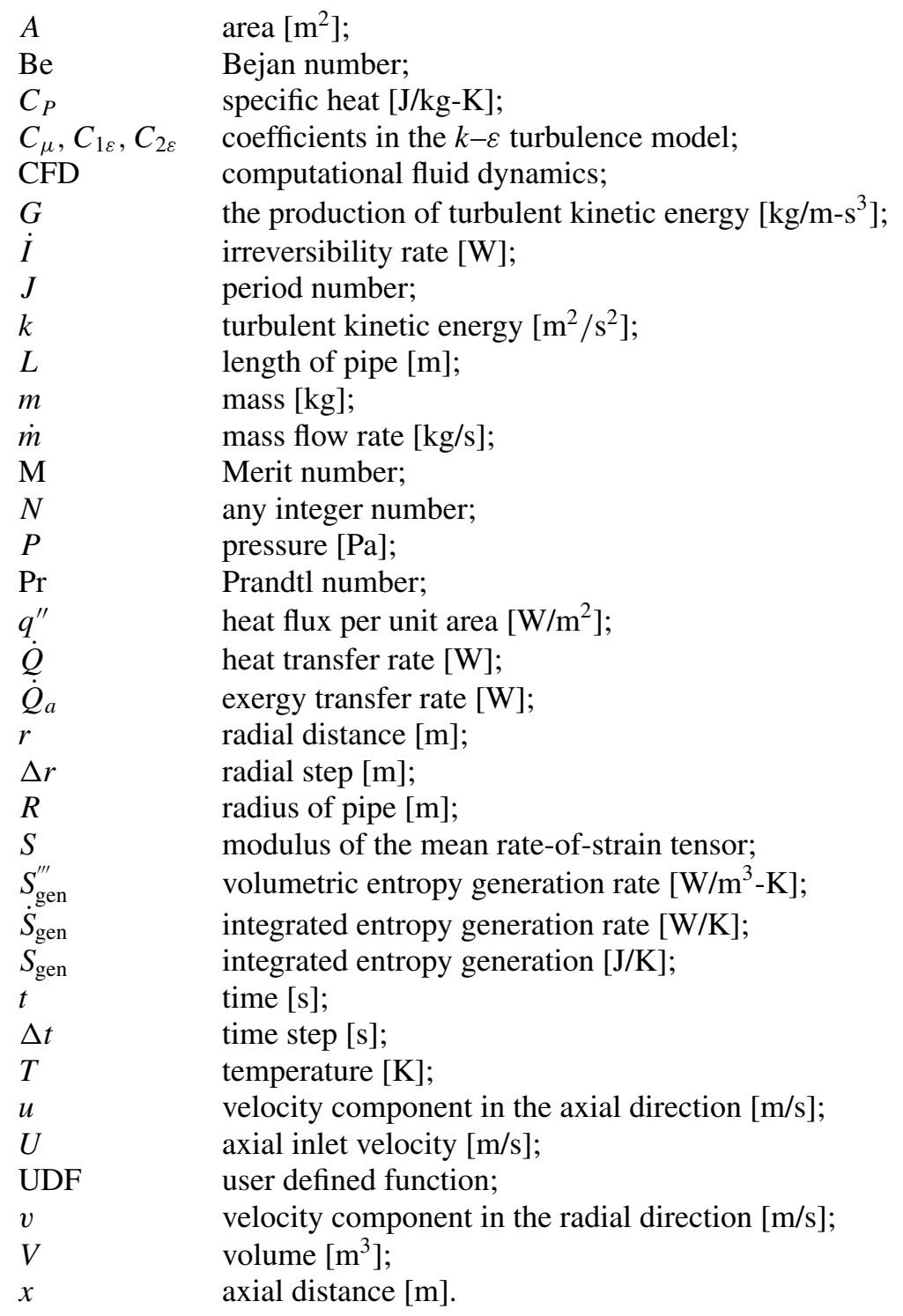

\section{Greek symbols}

$\begin{array}{ll}\varepsilon & \text { turbulent energy dissipation rate }\left[\mathrm{m}^{2} / \mathrm{s}^{3}\right] ; \\ \phi & \text { arbitrary variable; } \\ \Phi & \text { viscous dissipation; } \\ \lambda & \text { thermal conductivity }[\mathrm{W} / \mathrm{m}-\mathrm{K}] ; \\ \mu & \text { dynamic viscosity }[\mathrm{kg} / \mathrm{m}-\mathrm{s}] ; \\ \rho & \text { density }\left[\mathrm{kg} / \mathrm{m}^{3}\right] ; \\ \sigma_{k} & \text { turbulent Prandtl numbers for } k ;\end{array}$




$\begin{array}{ll}\sigma_{\varepsilon} & \text { turbulent Prandtl numbers for } \varepsilon \\ \tau & \text { period }[\mathrm{s}] ; \\ \psi & \text { arbitrary field variable. }\end{array}$

\section{Subscripts}

0 $\mathrm{amb}$

A

awa

eff

fric

$H$

heat

in

$j$

L

$\max$

M

out

$t$

$w$

initial;

ambient;

amplitude;

area-weighted average;

effective;

friction;

highest;

heat transfer;

inlet;

cell number;

lowest;

maximum;

mean or vertical shift;

out;

turbulent;

wall.

\section{References}

Abbassi H, Magherbi M, Brahim A B 2003 Entropy generation in Poiseuille-Benard channel flow. Int. J. Thermal Sci. 42: 1081-1088

Abu-Hijleh B A/K, Abu-Qudais M, Abu Nada E 1999 Numerical prediction of entropy generation due to natural convection from a horizontal cylinder. Energy 24: 327-333

Ahn K H, Ibrahim M B 1992 Laminar/turbulent oscillating flow in circular pipes. Int. J. Heat Fluid Flow 13: 340-346

Al-Zaharnah I T, Yilbas B S, Hashmi M S 2001 Pulsating flow in circular pipes - the analysis of thermal stresses. Int. J. Pressure Vessels Piping 78: 567-579

Bejan A 1996a Entropy generation minimization (Boca Raton, FL: CRC Press)

Bejan A 1996b Entropy minimization: the new thermodynamics of finite-size devices and finite-time processes. J. Appl. Phys. 79: 1191-1218

Brown D M, Li W, Kakac S 1993 Numerical and experimental analysis of unsteady heat transfer with periodic variation of inlet temperature in circular ducts. Int. Commun. Heat Mass Transfer 20: 883-899

Calmen M, Minton P 1977 An experimental investigation of flow in an oscillating pipe. J. Fluid Mech. 81: $421-431$

Cho H W, Hyun J M 1990 Numerical solutions of pulsating flow heat transfer characteristics in a pipe. Int. J. Heat Fluid Flow 11: 321-330

Cotta R M, Ozisik M N 1986 Laminar forced convection inside ducts with periodic variation of inlet temperature. Int. J. Heat Mass Transfer 29: 1495-1501

Demirel Y, Kahraman R 1999 Entropy generation in a rectangular packed duct with wall heat flux. Int. J. Heat Mass Transfer 42: 2337-2344

Faghri M, Javandi K, Faghri A 1979 Heat transfer with laminar pulsating flow in a pipe. Lett. Heat Mass Transfer 6: 259-270

Fluent 2003 Fluent User's guide, Version 6·1, Fluent Incorporated 
Haddad O M, Alkam M K, Khasawneh M T 2004 Entropy generation due to laminar forced convection in the entrance region of a concentric annulus. Energy 29(1): 35-55

Hyder S J, Yilbas B S 2002 Entropy analysis of conjugate heating in a pipe flow. Int. J. Energy Res. 26: $253-262$

Kurzweg U H 1985 Enhanced heat conduction in fluids subjected to sinusoidal oscillations. J. Heat Transfer 107: 459-462

Launder B E, Spalding D B 1972 Lectures in mathematical models of turbulence (London: Academic Press)

Mahmud S, Fraser R A 2003 The second law analysis in fundamental convective heat transfer problems. Int. J. Thermal Sci. 42: 177-186

Mahmud S, Fraser R A 2002 Thermodynamic analysis of flow and heat transfer inside channel with two parallel plates. Exergy, Int. J. 2: 140-146

Moschandreou T, Zamir M 1997 Heat transfer in a tube with pulsating flow and constant heat flux. Int. J. Heat Mass Transfer 40: 2461-2466

Mukherjee P, Biswas G, Nag P K 1987 Second-law analysis of heat transfer in swirling flow through a cylindrical duct. ASME J. Heat Transfer 109: 308-313

Peattie R A, Budwig R 1989 Heat transfer in laminar, oscillatory flow in cylindrical and conical tubes. Int. J. Heat Mass Transfer 32: 923-934

Sahin A Z 1998a Second law analysis of laminar viscous flow through a duct subjected to constant wall temperature. ASME J. Heat Transfer 120: 76-83

Sahin A Z 1998b A second law comparison for optimum shape of duct subjected to constant wall temperature and laminar flow. Heat Mass Transfer 33: 425-430

Sahin A Z 1998c Irreversibilities in various duct geometries with constant wall heat flux and laminar flow. Energy 23: 465-473

Sahin A Z 1999 Effect of variable viscosity on the entropy generation and pumping power in a laminar fluid flow through a duct subjected to constant heat flux. Heat Mass Transfer 35: 499-506

Sahin A Z 2000 Entropy generation in turbulent liquid flow through a smooth duct subjected to constant wall temperature. Int. J. Heat Mass Transfer 43: 1469-1478

Sahin A Z 2002 Entropy generation and pumping power in a turbulent fluid flow through a smooth pipe subjected to constant heat flux. Exergy, Int. J. 2: 314-321

Shuja S Z, Yilbas B S 2001 A laminar swirling jet impingement on to an adiabatic wall Effect of inlet velocity profiles. Int. J. Numer. Methods Heat Fluid Flow 11: 237-254

Shuja S Z, Yilbas B S, Budair M O, Hussaini I S 1999 Entropy analysis of a flow past a heat-generated bluff body. Int. J. Energy Res. 23: 1133-1142

Shuja S Z, Yilbas B S, Budair M O 2001a Local entropy generation in an impinging jet: minimum entropy concept evaluating various turbulence models. Comput. Methods Appl. Mech. Eng. 190: $3623-3644$

Shuja S Z, Yilbas B S, Iqbal M O, Budair M O 2001b Flow through a protruding bluff body-heat and irreversibility analysis. Exergy, Int. J. 1: 209-215

Shuja S Z, Yilbas B S, Budair M O 2002 Investigation into a confined laminar swirling jet and entropy production. Int. J. Numer. Methods Heat Fluid Flow 12: 870-887

Shuja S Z, Yilbas B S, Rashid M 2003 Confined swirling jet impingement onto an adiabatic wall, Int. J. Heat Mass Transfer 46: 2947-2955

Valueva E P, Popov V N, Romanova S Y 1993 Heat transfer under laminar pulsating flow in a round tube. Thermal Eng. 40: 624-631

Yapiicıi H, Kayataş N, Albayrak B, Baştürk G 2005 Numerical calculation of local entropy generation in a methane-air burner. Energy Conversion Manage. 46: 1885-1919

Yaws C L, Lin X Y, Bu L 1994 Calculate viscosities for 355 liquids. Chem. Eng. 101: 119-128

Yilbas B S, Shuja S Z, Budair M O 1999 Second law analysis of a swirling flow in a circular duct with restriction. Int. J. Heat Mass Transfer 42: 4027-4041 